\title{
Organizational Culture in the Financial Sector: Evidence from a Cross-Industry Analysis of Employee Personal Values and Career Success
}

\author{
André van Hoorn ${ }^{1}$
}

Received: 1 September 2015 / Accepted: 28 October 2015/Published online: 5 November 2015

(C) The Author(s) 2015. This article is published with open access at Springerlink.com

\begin{abstract}
We assess the organizational culture in the finance industry in relation to the global financial crisis and consider the potential of cultural change to improve the financial sector. To avoid (response) biases, we build on the person-organization fit literature and develop a novel, indirect method for assessing organizational culture that revolves around relationships between employees' personal traits and their career success in the industry or organization under study. We analyze personal values concerning the pursuit of private gain (self-enhancement values) versus personal values concerning caring for others (selftranscendence values) and consider whether employees that value self-enhancement more and self-transcendence less enjoy more career success relative to their peers when working in finance than when working in other industries. Results do not reveal any sort of cross-industry differences that would implicate the finance industry's culture in the financial crisis. Instead, we find the opposite, namely that strong self-enhancement values and weak self-transcendence values go together with less career success in the finance industry compared to other industries. Hence, if anything, the culture in the finance industry does not seem to resonate well with professionals that seek to pursue personal gain at the expense of clients' welfare. Implication is that cultural change has little potential to improve the financial system. Meanwhile, the method for assessing organizational culture indirectly by analyzing relationships between employees' traits and their career outcomes has
\end{abstract}

André van Hoorn

vanhoorn@gmail.com; A.A.J.van.Hoorn@rug.nl

1 Department of Global Economics \& Management, Faculty of Economics \& Business, University of Groningen, PO Box 800, 9700 AV Groningen, The Netherlands wider applicability, particularly when relying on scores or measures obtained directly from the people concerned is likely to render biased evidence.

Keywords Organizational culture - Financial crisis . Personal values $\cdot$ Employee outcomes $\cdot$ P-O fit $\cdot$ Cultural change

\section{Introduction}

With the financial sector playing a central role in the daily lives of individuals and organizations alike (Krippner 2005; Davis and Kim 2015), a key question following the global financial crisis (GFC) is how the financial system can be improved to decrease the likelihood of future crises and optimize the intermediation between suppliers of credit and credit seekers. This paper assesses the finance industry's culture in relation to the GFC and considers the potential of cultural change to improve the financial sector. Corporate or organizational culture, which we define straightforwardly as "the way we do things around here" (Bower 1966; Deal and Kennedy 1982), is widely recognized as an essential feature of the organizational environment, having strong effects on employees and their behavior (Pettigrew 1979; Schein 1992). Hence, it is only logical that the culture in the finance industry has been fiercely debated in the wake of the financial crisis. Professional commentators (Fox 2010; Lewis 2010; Friedman 2011), government officials (Stiglitz et al. 2010; Financial Crisis Inquiry Commission 2011) as well as academics (Boddy 2011; Santoro and Strauss 2012; Werner 2014) have been particularly concerned with the role of the finance industry's culture in promoting unethical behavior such as misleading customers, deliberately withholding 
information from clients and maximizing personal gain by putting the welfare of others at risk and other such malfeasances (ibidem). A study of laboratory behavior reports that bankers do not behave statistically significantly more dishonestly than other people do (Cohn et al. 2014), while other work finds that the personal values of finance professionals differ only trivially from the personal values of other people (Van Hoorn 2015). Meanwhile, systematic evidence on the actual organizational culture in the finance industry is lacking, although the quasi-experimental study by Cohn et al. (2014) does find that asking bankers about their professional background increases their dishonesty. A particular challenge is that the widespread criticism that the industry's culture has received in the wake of the crisis leads to all sorts of biases in information collected directly from the people concerned, professionals working in the finance industry. If we take the typical approach to measuring organizational culture, for instance, which is through employee questionnaires (Ashkanasy et al. 2000), we expect substantial biases in responses collected after the start of the GFC that are aggravated by the fact that people's ethical values are involved (Zerbe and Paulhus 1987; Randall and Fernandes 1991; Crane 1999). On the other hand, widely discussed cases of malfeasance mostly concern specific individuals and their behavior-Kweku Adoboli and Jérôme Kerviel are high-profile examples (Slater 2011) - rather than the actual culture of the organizations involved. Meanwhile, knowing the significance of the industry's culture as a factor in the GFC is critical to the formulation of effective financial sector reforms, preventing either an under- or overemphasizing of cultural change as a way to improve the current financial system (Central Bank of Ireland 2012; Financial Conduct Authority 2014).

Seeking to present an unbiased yet systematic assessment of the finance industry's culture in relation to the GFC, this paper develops an indirect method for assessing organizational culture that revolves around observing specific relationships between employee variables within the organization (or industry) under study. The idea, which has theoretical roots in the literature on person-organization (P-O) fit (O'Reilly et al. 1991; Kristof 1996), is simply that uncovering the personal traits that help or hamper employees achieve success in particular organizations is revealing of the organizational environments in these organizations, particularly their cultures.

For the practical implementation of this indirect method for assessing organizational culture, we consider individuals' personal values and their career success relative to their peers working in the same industry, notably their position in the corporate hierarchy. We compare the values-success relationship found for the finance industry with the values-success relationship found for other industries and look for cross-industry differences in this relationship that are consistent with the idea that the culture in the finance industry provides a better fit for employees willing to engage in unethical behavior than other industries do. Concretely, we focus on a specific set of basic human values (Schwartz and Bilsky 1987; Schwartz 1992), namely so-called self-enhancement values (the values associated with power, achievement, and the pursuit of personal gain) versus so-called self-transcendence values (the values associated with universalism, benevolence, and caring about other people's welfare). If the organizational culture in the finance industry is indeed unique and partly to blame for promoting the kind of malfeasances that brought down the global financial system, we expect that individuals with stronger self-enhancement and weaker self-transcendence values will be more successful relative to their industry peers when working in the finance industry than when working in other industries.

Data for our empirical analysis come from the European Social Survey or ESS (Jowell and Central Co-ordinating Team 2007), which, depending on the exact sample that we consider, covers up to 211,531 individuals. In different waves, the ESS has collected information on the basic values of respondents but also on their occupation, as well as on other individual features, including the number of subordinates that an individual has. We operationalize a person's career success as his/her position in the corporate hierarchy measured by this latter variable and further use the occupational data to distinguish between professionals working in the finance industry (FIs) and people working in other sectors, meaning every individual that is not working as a professional in the finance industry (non-FIs).

Results do not reveal any cross-industry differences consistent with the idea that the organizational culture in the finance industry stands out from the organizational culture in other industries in a way that implicates the finance industry's culture in the GFC. In fact, we find the opposite, namely that, compared to other industries, in the finance industry strong self-enhancement values and weak self-transcendence values go together with less rather than more career success relative to one's peers working in the same industry. Hence, if anything, the organizational culture in the finance industry does not seem to resonate well with professionals that seek to pursue their own personal gain at the expense of others. In terms of practical implications, we conclude that cultural change has only limited potential to address the prevalence of malfeasance in the finance industry. Instead, realistic and successful financial reform asks for the redesigning of governance structures and regulations as the factors with the most potential to bring favorable change to the sector.

This paper makes two chief contributions. First, and most obviously, the paper brings important insight on the 
much-debated issue of the cultural roots of the GFC and the potential of cultural change to improve the financial system. By presenting systematic evidence on the finance industry's organizational culture vis-à-vis organizational cultures in other industries, we help clarify the significance of cultural change as part of reforms meant to improve the current financial system. Second, we think that in developing our indirect method for assessing the culture in the finance industry, we also make an important methodological contribution. Although our approach is clearly not without limitations, we find that the specific method that we have developed for this paper is a promising addition to the existing toolkit for studying organizational cultures. As the approach is indirect, i.e., observing organizational culture in the form of patterns of variation rather than measuring it directly, the method would be particularly useful whenever response biases are likely to invalidate traditional approaches to culture assessment, for instance, face-to-face interviews or employee surveys. Hence, we call for more work to develop the method further, notably by theorizing on the set of interrelationships between employee traits and work outcomes, which needs to be considered in order to provide a comprehensive characterization of organizations' culture that is comparable to the established organizational culture frameworks.

\section{Organizational Culture in the Finance Industry}

\section{Review of Prior Research}

Although much debated, there have been few systematic studies of the organizational culture in the finance industry. Two studies stand out, although as we shall explain, it is unclear what exactly these studies can tell us about the finance industry's culture.

First, Cohn et al. (2014) report on a laboratory experiment involving bankers and nonbankers with material incentives for dishonest behavior conducted in 2012. They find that, on average, bankers are not statistically significantly more prone to behaving dishonestly than people in other occupations are. However, adding a treatment by asking one group of bankers to make explicit statements about their professional background did have a statistically significant effect. Specifically, the group of bankers that was asked about their professional background was found to be statistically significantly more prone to dishonest behavior than the control group of bankers that was not asked about their professional background was. Cohn et al. (2014) attribute this effect to the culture in the finance industry, concluding that this culture makes employees behave more dishonestly.

Second, Van Hoorn (2015) considers the personal values of professionals in the finance industry vis-à-vis the personal values of the general population. To prevent biased responses, he uses survey data collected before the start of the GFC in 2007. Results indicate that finance professionals attach only trivially more value to power and achievement (self-enhancement) and only trivially less value to the welfare of others (self-transcendence) than the general population does. Moreover, these differences disappear completely or are overturned once standard individual characteristics such as level of education are added as control variables. Van Hoorn (2015) thus finds that malfeasances in the finance industry and the GFC would have occurred regardless of the specific individuals employed in the industry.

Although interesting and important, our concern is that, in the end, these two studies do not actually speak to the culture in the finance industry. First, laboratory experiments involving culture such as the study by Cohn et al. (2014) are quasi-experimental in the sense that subjects are not randomly assigned to different organizational cultures, which would be required for a genuine experiment (Shadish et al. 2002; Matsumoto and Van de Vijver 2011; Van Hoorn 2012). Hence, it is not possible to ascertain whether any treatment effect found is indeed causally due to culture or due to some other factor or mechanism. Since Cohn et al. (2014) conducted their study in 2012, a particular concern is the possibility that the collective reputation of bankers, which has been severely tarnished in the wake of the crisis (Roulet 2015), has interacted with the authors' treatment and ended up biasing the results. The reason is that belonging to a group with a poor collective reputation undermines the incentive for individual group members to behave honestly (Tirole 1996). Hence, we expect that asking people about their finance background after the crisis increases dishonesty, but not because they were reminded about the culture in the finance industry, but because these bankers were less motivated to behave honestly, once their banker identity was brought out in the open. In fact, if collective reputation indeed accounts for the effect found by Cohn et al. (2014), we expect that a similar treatment effect occurs among any group of individuals that, like bankers, has a poor collective reputation in the eyes of the public, once their group identity has been brought out in the open. This, in turn, is confirmed by another laboratory study of dishonesty but involving prisoners rather than bankers (Cohn et al. 2015). ${ }^{1}$

Second, it is similarly unclear how informative the results by Van Hoorn (2015) are of the culture in the finance industry (rather than of the individuals working in this industry). The reason is that the culture of an

\footnotetext{
$\overline{1}$ Specifically, this study reports that inmates whose prisoner identity was made explicit behaved less honestly than the control group did, but does not attribute this result to "prison culture."
} 
organization comprises a whole lot more than the average of the personal values of the individual employees that work for the organization (Pettigrew 1979; Deal and Kennedy 1982; Schein 1992). Hence, while Van Hoorn (2015) effectively shows that the personal values of professionals in the finance industry cannot be readily blamed for the financial crisis (obvious individual wrongdoings notwithstanding; e.g., Slater 2011), his results do not provide us with clear evidence on the significance of actual organizational culture in the finance industry in relation to this crisis.

\section{The Finance Industry's Culture in the Wake of the Crisis}

From the above review, we conclude that, as is, the literature lacks clear, systematic evidence on the culture in the finance industry and, particularly, the significance of this culture as a factor in the GFC. Nevertheless, because of all the other, nonsystematic information that has become available, we do have a clear idea of the specific features of the finance industry's culture that we need to study in order to ascertain whether this culture may be blamed for the GFC and assess the potential of cultural change to improve the financial system. Specifically, (anecdotal) evidence on the malfeasances that happened in the sector (e.g., Financial Crisis Inquiry Commission 2011; Friedman 2011; Santoro and Strauss 2012), raises suspicions as to whether and to what extent the industry's culture has been promoting unethical behavior by individual employees. We therefore think that systematic assessment of the finance industry's culture in relation to the GFC requires us to gather evidence that speaks to the way in which the industry has been uniquely conducive to individual employees that put the maximization of their personal gain above the best interests of the clients served by the industry. This idea, in turn, leads us to posit the following proposition as a way of summarizing the post-crisis criticism of the organizational culture in the finance industry:

Proposition The culture in the finance industry has been uniquely conducive to organizational members behaving unethically, to the extent that this culture is partly to blame for the global financial crisis.

The practical implication of this proposition is that cultural change in the finance industry provides an important route to improving the financial system, decreasing the likelihood of future crises and optimizing the intermediation between suppliers of credit and credit seekers.

How exactly we bring the above proposition to data to allow for a formal test requires some explication. Hence, in the next section we first elaborate on the idea of considering the relationship between employees' personal traits and their career success as a method for assessing organizational culture before presenting our hypothesis.

\section{Empirical Approach and Hypothesis}

\section{Organizational Culture, Employees' Personal Values, and Career Success}

An Indirect Approach to Assessing Organizational Culture

The most common approach to measuring organizational culture is through employee questionnaires where the responses to different items are combined to construct scores on a comprehensive set of dimensions (Ashkanasy et al. 2000). In principle, we could use the same approach, adding a cross-industry comparative perspective as a way of assessing whether the culture in the finance industry is indeed unique in a way that implicates this culture in the GFC. ${ }^{2}$ However, we deviate from this established approach for one simple reason, which is that we do not want to assess the culture in the finance industry on the basis of scores or measures obtained directly from the people concerned. Given the fierce debate on the culture in the finance industry that has followed the GFC (Roulet 2015), we find that the risk of biased results is simply too great when we allow post-crisis survey answers by finance professionals (or laboratory behaviors for that matter) to have direct bearing on our assessment (cf. Randall and Fernandes 1991; Crane 1999). Our indirect method of looking at cross-industry differences in the relationship between personal traits and employee outcomes, in contrast, would still rely on data collected from employees in the sector, but none of these data would have direct bearing on our assessment. Instead, the actual assessment of the culture in the industry occurs completely outside the mind of the people concerned, by researchers establishing relationships between different variables. Ex-post combining of data on employees' personal traits with data on their work outcomes enables us to estimate the relationship between these two types of variables and use the pattern that emerges to make unbiased inferences about the culture of the industries involved.

Obviously, the advantage of avoiding biased results comes at the expense of using a novel method that has not yet proven itself. However, we find that our method has a strong theoretical basis as well as much intuitive appeal. To

\footnotetext{
2 The rationale for adding this cross-industry comparative perspective is, of course, that we can only blame the culture in the finance industry for the GFC if this culture is, in fact, significantly different from the culture in other industries.
} 
start with the latter, imagine the following two organizations. In the first organization, it turns out that the most egotistical employees are also the ones that have the most successful careers within the organization. In the second organization, however, the most egotistical employees are the ones that have the least successful careers within the organization. Now imagine what it must be like to be an employee in one of these organizations and, especially, what these employees would say about their respective organizational environments. Clearly, we would expect rather different answers, referring to rules, routines, procedures etc. deeply embedded in these organizations. Accordingly, we think that it makes a lot of sense to assess the culture of organizations on the basis of the relationship between employees' personal traits and the extent of their career success relative to their peers.

Beyond this intuitive appeal, our approach has theoretical roots in the literature on the effects of $\mathrm{P}-\mathrm{O}$ on employee outcomes (O’Reilly et al. 1991; Kristof 1996). This literature provides ample evidence that the compatibility between employees' traits, such as their personality or values on the one hand, and organizational culture on the other hand, is a powerful determinant of work outcomes (Chapman et al. 2005; Kristof-Brown et al. 2005), including employees' workplace authority (Anderson et al. 2008). Our approach to assessing the organizational culture in the finance industry is rooted in this literature, specifically the logic that certain personality or value traits are critical to working successfully in some organizational cultures, while these same traits hamper individuals' ability to work successfully in other organizational cultures. Taking the influence of $\mathrm{P}-\mathrm{O}$ fit on employee outcomes as a given, we use inter-organizational or cross-industry differences in the relationship between personal traits and work outcomes to make inferences about the culture of the organizations or industries involved.

An important open parameter in the design of a study that assesses organizational culture indirectly by comparing trait-outcome relationships is the specific traits and employee outcomes that one considers. Following the above example of two hypothetical organizations, we find that one of the most suitable employee outcomes to look at is career success relative to one's peers working in the same organization. For sure, there are many different employee outcomes-as also considered by the literature on P-O fit - that could be used. However, career success seems a most relevant one, as career success provides a strong motivation for employees to behave in a certain way, including, potentially, misleading customers, deliberately withholding information from clients, and other such unethical behaviors. Similarly, we find that traits that speak to people's motivations are most suitable for consideration, as this type of traits seems more relevant in relation to organizations' culture than, for instance, experience or educational degree. Moreover, we think it more appropriate to consider broad mental orientations rather than narrow constructs that speak to only one specific human disposition. Concretely, we thus deem it best to consider employees' personal values, which have the attractive feature that they transcend specific actions or situations (Schwartz 1992).

Meanwhile, values are rather complex constructs. Hence, before turning to the formulation of our hypothesis, we first discuss exactly which values we deem appropriate for assessing organizational culture in general and for assessing the culture in the finance industry in relation to the GFC in particular.

\section{Values}

Values are concepts about desirable end states or behavior that provide guidance to individuals in evaluating and choosing between alternative courses of action across a range of situations (Schwartz and Bilsky 1987, p. 551). Although a variety of approaches to conceptualizing values exists, the literature has been converging on a standard framework of universal values constructed with the aim of capturing the complete spectrum of human motivations. The development of this framework is mostly the work of Shalom Schwartz (e.g., Schwartz and Bilsky 1987, Schwartz 1992) and revolves around 10 basic values. The description of these 10 basic values is as follows (taken from Schwartz et al. 2001, p. 521): Power refers to social status and prestige, control or dominance over people and resources; Achievement refers to personal success through demonstrating competence according to social standards; Hedonism refers to pleasure and sensuous gratification for oneself; Stimulation refers to excitement, novelty, and challenge in life; Self-Direction refers to independent thought and action-choosing, creating, exploring; Universalism refers to understanding, appreciation, tolerance, and protection for the welfare of all people and for nature; Benevolence refers to preservation and enhancement of the welfare of people with whom one is in frequent personal contact; Tradition refers to respect, commitment, and acceptance of the customs and ideas that traditional culture or religion provide the self; Conformity refers to restraint of actions, inclinations, and impulses likely to upset or harm others and violate social expectations or norms; and, finally, Security refers to safety, harmony, and stability of society, of relationships, and of self. The 10 basic values combine to form four higher-order subdimensions, namely self-enhancement (Power and Achievement), self-transcendence (Benevolence and Universalism), openness-tochange (Self-Direction, Stimulation, and Hedonism) and conservation (Tradition, Conformity, and Security). 
Finally, the framework of universal human values comprises two overarching values dimensions, which combine the opposing subdimensions: self-transcendence versus self-enhancement and openness-to-change versus conservation. The opposition of subdimensions reflects the structure of human values, which is that values can be mutually compatible or incompatible. Compatibility thereby refers to the possibility of achieving certain values simultaneously. Power and Achievement are compatible with each other, for instance, but not with Universalism and Benevolence (and vice versa).

Any of the basic values or values dimensions identified in the framework of universal human values may predict a person's career success (cf. England and Lee 1974; Watson and Williams 1977). However, for assessing the culture in the finance industry in relation to the GFC, we are interested in a specific set of values, namely the basic values that have most direct bearing on the malfeasances that have been linked to the GFC (e.g., Stiglitz et al. 2010; Financial Crisis Inquiry Commission 2011). Following Van Hoorn (2015), we find that there are four such values, namely Power, Achievement, Benevolence, and Universalism. Power and Achievement are thereby likely to capture motivations that make individuals more prone to malfeasance, while Benevolence and Universalism are likely to capture motivations that make individuals less prone to malfeasance. However, as these four basic values combine into the subdimensions of self-enhancement (SE) and selftranscendence (ST) as well as the overarching self-transcendence versus self-enhancement (ST/SE) dimension, in our empirical analysis we focus on these latter three value constructs.

\section{Hypothesis}

Our hypothesis derives directly from the proposition that the culture in the finance industry stands out from the culture in other industries in a way that implicates this culture in the GFC. Comparing the values-success relationship in the finance industry with the values-success relationship in other industries allows us to check whether these two relationships differ in a way that is consistent with the idea that the finance industry's culture promotes unethical behavior more than organizational cultures elsewhere do. Following our proposition on the culture in the finance industry, specifically this culture's effect on malfeasance and employees putting the maximization of own personal gain above the interests of the clients that they serve, we expect that individuals with strong ST values/weak SE values will have a hard time working in this industry. Individuals with strong SE values/weak ST values, on the other hand, will thrive in the finance industry. More concretely, and taking in the literature that relates $\mathrm{P}-\mathrm{O}$ fit to employee outcomes, we posit that individuals with strong SE values have a better fit with the finance industry and therefore enjoy more career success in this industry than individuals with weak SE values do. And, similarly, we expect that individuals with strong ST values have a poorer fit with the finance industry and therefore enjoy less career success in this industry than individuals with weak ST values do. Moreover, we posit that the finance industry is, overall, much more appreciative of strong $\mathrm{SE}$ values and much more dismissive of strong ST values than other industries are. Hence, we translate the proposition presented in the previous section into the following hypothesis (H1):

Hypothesis 1 Career success in the finance industry correlates more positively with the strength of individuals' self-enhancement values and more negatively with the strength of individuals' self-transcendence values than career success in other industries does.

We test this hypothesis below. First, however, we discuss our sample and measures and details of our statistical method, specifically the empirical model that we estimate to test this hypothesis.

\section{Sample, Measures, and Statistical Method}

\section{Sample}

Our data come from the first six waves of the European Social Survey or ESS (Jowell and Central Co-ordinating Team 2007). The ESS is a bi-annual survey of nationally representative samples of mostly European countries. The survey started in 2002 so that we have data collected in 2002, 2004, 2006, 2008, 2010 and 2012. For our baseline analysis, we use data collected in all these years. However, as a robustness check, we also consider data collected before the start of the GFC only, meaning data collected between 2002 and 2006. The countries in our main sample are Austria, Belgium, Bulgaria, Switzerland, Cyprus, Czech Republic, Germany, Denmark, Estonia, Spain, Finland, France, United Kingdom, Greece, Croatia, Hungary, Ireland, Israel, Iceland, Italy, Lithuania, Luxembourg, Netherlands, Norway, Poland, Portugal, Russia, Sweden, Slovenia, Slovakia, Turkey, and Ukraine (32 in total).

The data collected by the ESS varies from measures of respondents' basic values to a variety of demographic variables and other background characteristics, including respondents' occupation and the number of subordinates that they have. Our sample comprises all individuals with nonmissing data on the relevant variables. Depending on choices regarding the time of data collection (see above) and the variables considered, the sample for the empirical 
analysis can cover up to 211,531 individuals (our main sample). The ESS is the source for all our data, both the dependent and the independent variables in our estimating equation. Note, however, that common method bias is not a problem, as our interest is not so much in explaining differences in absolute levels of a variable, but in comparing relationships between variables across different groups, specifically professionals working in finance (FIs) vis-à-vis people working in other industries (non-FIs). Additionally, common method bias would be most problematic when both the dependent and independent variables in the analysis concern subjective assessments, which is typically not the case in our analysis. More information on the ESS and the variables included in this survey is available from the ESS website, http://www.europeansocialsurvey.org.

\section{Measures}

\section{Classification of Professionals Working in the Finance Industry}

The dependent variable in our empirical analysis concerns individuals' career success. Similarly, the main independent variable in our analysis concerns individuals' personal values. Nevertheless, the key variable in our analysis is the measure that we use to identify respondents as working in the finance industry (FI) or not (non-FI). We follow Van Hoorn (2015) and create a dummy variable to classify individuals as FI (score of 1 ) or not (score of 0 ) on the basis of four-digit occupational codes from the International Standard Classification of Occupations (ISCO). The first five waves of the ESS (2002, 2004, 2006, 2008, and 2010) classify people's occupation on the basis of the 1988 ISCO classification (ISCO88), which is also used by Van Hoorn (2015). In the 1988 classification, the occupational categories that we classify as FIs are: Finance and sales associate professionals (ISCO88 3410); Securities and finance dealers and brokers (ISCO88 3411); Business services agents and trade brokers (ISCO88 3420); and Trade brokers (ISCO88 3421) (see Van Hoorn 2015). For Wave 6, the ESS switched to the 2008 ISCO classification (ISCO08). In this classification, the occupational categories that we classify as FIs are: Financial and investment advisers (ISCO08 2412) and Securities and finance dealers and brokers (ISCO08 3311). Throughout, our identification criterion is strict in the sense of only considering professionals in the finance industry and not support staff or other types of employees, as these are not the kind of employees whose behavior has been blamed for the GFC.

Overall, we have almost 800 individuals classified as FI in our analysis, where the exact number depends on the sample chosen and the other variables (e.g., control variables) included in the analysis. However, for one of our robustness checks, we also consider a still narrower classification of FIs, for which we re-classify Finance and sales associate professionals (ISCO88 3410) and Business services agents and trade brokers (ISCO88 3420) as non-FIs. In this case, we have almost 450 individuals classified as FIs in our analysis. More information on the ISCO88 and ISCO08 classification can be found on the website of the ESS that we mentioned earlier and, particularly, the website of the International Labour Organisation, http://www. ilo.org/public/english/bureau/stat/isco.

\section{Dependent Variable: Employee Career Success}

The dependent variable in our empirical analysis is the success that an individual is able to achieve in his/her professional career. Of course, career success can be defined and operationalized in a variety of ways and, at any rate, is a highly subjective concept. We measure an individual's career success by the number of subordinates that he or she has, if any. This measure derives from the item included in the ESS that asks respondents how many people they are/were responsible for in their job. In case the respondent is not responsible for supervising the work of other employees, the number of subordinates equals 0 . Because this specific measure is left-censored, we apply a simple logarithmic transformation. However, because we cannot take the logarithm of 0 , we first add 1 to the number of subordinates that the respondent has and then take the natural logarithm of the resulting sum.

To assess the robustness of our results we also consider two alternative indicators of an individual's career success. The first of these concerns the amount of authority that the respondent has at his/her place of work. We construct this measure as the principal component of two items in the ESS asking respondents about the autonomy and the influence that they have at their job. The first item reads as follows: "please say how much the management at your work allows/allowed you to decide how your own daily work is/was organised?" where answers can range from 0 , I have/had no influence to 10 , I have/had complete control. The second item similarly reads: "please say how much the management at your work allows/allowed you to influence policy decisions about the activities of the organisation?" where answers can also range from 0, I have/had no influence to 10 , I have/had complete control. Both these items have been used in studies of the quality of jobs and workplace practices (e.g., Esser \& Olsen, 2012). More generally, these items tap into the core features of a job as identified in the literature on job design and job characteristics (Hackman and Oldham 1975). Cronbach's alpha for the combination of these two measures equals 0.783 , which signals more than adequate internal consistency (George and Mallery 2003). 
Table 1 Descriptive statistics

\begin{tabular}{|c|c|c|c|c|c|c|c|c|c|}
\hline & \multicolumn{3}{|c|}{ Whole sample } & \multicolumn{3}{|c|}{$\begin{array}{l}\text { Finance industry } \\
\text { professionals }\end{array}$} & \multicolumn{3}{|c|}{$\begin{array}{l}\text { Finance industry } \\
\text { professionals, narrow } \\
\text { classification }\end{array}$} \\
\hline & Mean & $N$ & SD & Mean & $N$ & SD & Mean & $N$ & SD \\
\hline Finance industry professional $(0 / 1)$ & $.38 \%$ & 213,283 & $6.14 \%$ & & & & & & \\
\hline Finance industry professional, narrow classification $(0 / 1)$ & $.21 \%$ & 213,283 & $4.59 \%$ & & & & & & \\
\hline Number of subordinates & 6.57 & 211,531 & 99.6 & 3.93 & 797 & 14.5 & 3.38 & 446 & 13.8 \\
\hline Workplace authority (principal component) & 0 & 182,553 & 1 & .38 & 674 & .85 & .38 & 376 & .87 \\
\hline Position in corporate hierarchy & 1.53 & 206,174 & 1.35 & 1.64 & 783 & 1.38 & 1.62 & 435 & 1.33 \\
\hline Self-transcendence versus self-enhancement (ST/SE) values & 1.27 & 213,283 & 1.11 & 1.08 & 806 & 1.10 & 1.01 & 450 & 1.15 \\
\hline Self-transcendence (ST) values & .63 & 213,283 & .52 & .58 & 806 & .50 & .53 & 450 & .52 \\
\hline Self-enhancement (SE) values & -.64 & 213,283 & .73 & -.50 & 806 & .73 & -.47 & 450 & .76 \\
\hline Years of education & 12.5 & 213,283 & 3.97 & 14.1 & 806 & 3.48 & 14.4 & 450 & 3.34 \\
\hline Total hours normally worked per week & 40.4 & 213,283 & 13.9 & 40.8 & 806 & 12.4 & 40.5 & 450 & 12.2 \\
\hline Data collected before start of crisis $(0 / 1)$ & $43.7 \%$ & 213,283 & $49.6 \%$ & $47.8 \%$ & 806 & $50.0 \%$ & $38.4 \%$ & 450 & $48.7 \%$ \\
\hline $\begin{array}{l}\text { Paid cash with no receipt to avoid tax }(1, \text { never }-5 \text {, five or } \\
\text { more times) }\end{array}$ & 1.86 & 33,170 & 1.51 & 1.83 & 146 & 1.40 & 1.81 & 63 & 1.27 \\
\hline $\begin{array}{l}\text { Made exaggerated or false insurance claim }(1, \text { never- }-5 \text {, five } \\
\text { or more times) }\end{array}$ & 1.33 & 33,712 & 1.19 & 1.34 & 146 & 1.16 & 1.14 & 63 & .67 \\
\hline
\end{tabular}

For our second alternative measure of career success, we seek to take into account that one's position in the corporate hierarchy is not only a function of the absolute number of subordinates that one has but also the number of subordinates relative to the total size of the organization for which one works. The ESS asks respondents about the size of the organization that they work for using the following item: "Including yourself, about how many people are/ were employed at the place where you usually work/worked." There are five possible answer categories: (i) Under 10; (ii) 10-24; (iii) 25-99; (iv) 100-499; and (v) 500 or more. Since organization size is measured on a cardinal scale, we deem it unwise to simply divide the number of subordinates by the size of the organization to construct our second alternative measure of professional career success. Instead, we first convert both the number of subordinates measure and the organization size measure into percentile scores, before taking their division. Table 1 presents descriptive statistics for all three measures of employee career success that we consider, both for the sample as a whole and for the subsamples of FIs only.

\section{Main Independent Variables: Self-Enhancement and Self- Transcendence Values}

As indicated, the personal values that we consider derive from the standard framework of universal human values. We operationalize the basic values and higher-order dimensions in this framework using the 21-item Portrait Values Questionnaire or PVQ (Schwartz et al. 2001). The term "portrait" thereby refers to the specific way in which the PVQ elicits values from respondents, namely by asking respondents to describe themselves in comparison to a portrait presented to them by the interviewer. Answers are given on a Likert-type scale, allowing respondents to indicate how much the described person is like them (1, Very much like me-6, Not like me at all). Follow the standard recoding protocol for the PVQ, we ipsatize ratings on the separate items of the PVQ by subtracting the average score of the respondent on all the items included in the PVQ. The reason is that the framework of universal human values finds that values have a relative priority, meaning that values are only important or unimportant relative to other values. Hence, an individual may indicate that he/she finds money and material possessions unimportant but may attach even less importance to the well-being of friends. To calculate SE and ST values, we subsequently first calculate the underlying basic values: Power and Achievement (SE values); and Benevolence and Universalism (ST values). ${ }^{3}$ Finally, we calculate ST/SE scores by subtracting an individual's SE score from his/her ST score. Table 1 presents descriptive statistics on the resulting measures.

As stated, the reason for considering the SE and ST values from the framework of universal human values (and not other basic values) is that these specific values have a clear conceptual match with the kind of malfeasances that have come to be associated with the GFC (cf. Van Hoorn 2015). This conceptual match has an empirical counterpart,

\footnotetext{
3 The exact wording of the nine portraits used to measure these values is available on request.
} 
however, as there is ample evidence demonstrating a link between individuals' SE and ST values and such concrete behaviors as sharing and helping as well as delinquency and shoplifting (see Schwartz 2009 for a survey). However, a possible critique of the personal values that we consider is that such broad dispositional measures are, in fact, rather far removed from the concrete malfeasances that have come to be associated with the finance industry in general and the GFC in particular. Hence, as a robustness check, we also conduct our main empirical analysis replacing our values measures with two behavioral measures. These two alternative measures derive from items included in the 2004 wave of the ESS that ask individuals how often they have engaged in a particular type of dishonest behavior during the last 5 years, namely (i) made an exaggerated or false insurance claim or (ii) paid cash without a receipt to avoid some tax. Answers can range from 1, Never to 5, Five or more times so that a higher score indicates more dishonesty. ${ }^{4}$ Table 1 again presents descriptive statistics. As the data on insurance fraud and tax fraud have only been collected in 2004, our sample is much smaller when considering these measures than when considering individuals' basic values.

\section{Control Variables}

To check the robustness of some of our results and to extend our main analysis, we typically control for various traits of individuals other than their values. These variables concern some standard demographics as well as other personal traits that may play a role in the workplace. To start with the former, we consider both individuals' sex $(1=$ male $)$ and age. We calculate age by combining the year of data collection with the answer on the ESS questionnaire item asking respondents about their year of birth. When adding control variables we include a linear and a quadratic age term. Education is a first of the other personal traits that we consider. When adding educational controls we add both a set of dummy variables to indicate level of education (completed elementary education, incomplete secondary education, etc.; eight categories in total) and a continuous measure of the years of education that the individual has. We further take into account differences in working hours, finding that the amount of time that someone invests in his/ her job likely correlates with both career success and

\footnotetext{
${ }^{4}$ We have also calculated the correlations between the measures of insurance fraud and tax fraud and the basic values from the framework of universal human values. These correlations equal -0.03 and -0.05 for ST values, 0.05 and 0.08 for SE values, and -0.05 and -0.08 for ST/SE values ( $p$ values equal 0.00 in all cases; $n=42,437$ for insurance fraud, and $n=41,691$ for tax fraud), providing further support for considering these specific values in our analysis.
}

personal values. Finally, we control for the nature of the individual's employment relation, notably whether someone is self-employed or not, and country fixed effects. For both these factors, we construct a set of dummy variables, selecting one category as the reference category.

To save space, Table 1 presents descriptive statistics for a selected set of control variables only. Descriptive statistics for the nonreported control variables are available on request.

\section{Statistical Method}

To test our hypothesis, we use regression analysis. The dependent variable is the career success of individual $i$, which we denote by $\mathrm{S}_{\mathrm{i}}$. Similarly, the main independent variable in our analysis concerns the personal values of the individual, which we denote by $\mathrm{V}_{\mathrm{i}}$. Chief feature of $\mathrm{H} 1$ is that it involves a comparison between career success in the finance industry and career success in other industries. We incorporate this feature in our empirical model through an interaction term that allows the relationship between people's values and career success to vary across industries, specifically the finance industry vis-à-vis all other industries. Using $\mathrm{FI}_{\mathrm{i}}$ to refer to the dummy variable indicating whether the individual is a professional working in the finance industry or not, the resulting model is given by

$\mathrm{S}_{\mathrm{i}}=\beta_{0}+\beta_{1} \mathrm{~V}_{\mathrm{i}}+\beta_{2}\left(\mathrm{~V}_{\mathrm{i}} \times \mathrm{FI}_{\mathrm{i}}\right)+\beta_{3} \mathrm{FI}_{\mathrm{i}}+\beta_{4} \mathrm{X}_{\mathrm{i}}+\varepsilon_{\mathrm{i}}$,

Although this empirical model incorporates a direct effect of people's values on career success, the most important term is the interaction term involving individuals' industry of employment and their personal values $\left(\mathrm{V}_{\mathrm{i}} \times \mathrm{F}_{\mathrm{i}}\right)$. Obviously, the model also controls for the direct effect of being employed in the finance industry. Practically, Eq. 1 thus provides a model for predicting individuals' career success relative to peers active in the same industry. $\mathrm{H} 1$ is confirmed when $\beta_{2}$ is statistically significantly negative for ST and ST/SE values and statistically significantly positive for SE values. In that case, the finance industry appears more appreciative of values directed toward personal gain (selfenhancement) and less appreciative of values directed toward the well-being of others (self-transcendence) than other industries are (and vice versa in case $\beta_{2}$ is statistically significantly positive for ST and ST/SE values and statistically significantly negative for SE values). Similarly, when using our two alternatives to personal values, the measures of insurance fraud and of tax fraud, respectively, $\mathrm{H} 1$ is confirmed when $\beta_{2}$ is statistically significantly positive.

To be sure, our statistical method, as well as the fact that we consider individuals' career success as the dependent variable, appears sensitive to selection issues. Because of classic attraction, selection, and attrition effects (e.g., Schneider 1987), at any point in time, the group of people (not) working in the finance industry is not a random 
sample but comprises people that are, to a certain extent, selected into this industry (or the other industries) on purpose. In fact, following the importance of $\mathrm{P}-\mathrm{O}$ fit for employee outcomes, people are partly attracted to a particular industry because their personal value traits have a good match with the organizational culture in this industry. As a consequence, a bias would occur if we were to compare the career success of FIs with a certain set of values with the career success of non-FIs with the same set of values. However, this is not what we actually do in our analysis, as the comparison that we draw is between the career successes of individuals with different sets of values that are all working in the same industry. And because the comparison that we make is between individuals that have all underwent the same process of attraction, selection, and attrition, our analysis is not biased on the count of some sort of selection problem. Meanwhile, we have also formally tested whether the model that determines whether someone is an FI or not is independent of the model that determines someone's career success (Heckman 1979), finding that we could not reject the null hypothesis of independence at usual levels of statistical significance.

\section{Empirical Results}

\section{Baseline Results}

To start, we first estimate the simple relationship between individuals' personal values and the number of subordinates that they have, also adding an interaction term involving the industry in which the individual is employed (FI versus non-FI) (Models 1-3 in Table 2). Results show that scoring higher on self-transcendence (ST) and selftranscendence versus self-enhancement (ST/SE) values is associated with having fewer subordinates, on average, while this association is positive for self-enhancement (SE) values. As we would expect, these correlations remain when adding the interaction terms that allow the size and the sign of these correlations to differ between the finance industry and other industries (Models 4-6 in Table 2).

More importantly, the estimated coefficients for the interaction terms (Models 4-6) consistently indicate that people with stronger SE values and weaker ST values do not enjoy more career success relative to their industry peers when they are working in the finance industry than when they are working in other industries. Hence, the results do not support $\mathrm{H} 1$ and, in fact, almost the opposite pattern than the pattern predicted by $\mathrm{H} 1$ holds. Scoring higher on ST or ST/SE values has a statistically significantly $(p<0.1)$ less negative effect on the number of subordinates that someone has when working in the finance industry than when working in other industries (Models 4 and 5). Similarly, having stronger SE values has a less positive effect on career success in the finance industry than in other industries, although in this case the difference, as measured by the coefficient for the interaction term, is not statistically significant at usual levels $(p=0.15)$ (Model 6). In terms of effect size, the coefficients for the interaction terms are typically strong enough to overturn a positive or negative direct effect of a set of personal values on individuals' career success. As an example, while ST/

Table 2 Which industry's culture fits better with strong self-enhancement and weak self-transcendence values?

\begin{tabular}{|c|c|c|c|c|c|c|}
\hline $\begin{array}{l}\text { Dependent variable }=\text { number of subordinates that } \\
\text { respondent has }\end{array}$ & Model 1 & Model 2 & Model 3 & Model 4 & Model 5 & Model 6 \\
\hline Self-transcendence versus self-enhancement values (ST/SE) & $\begin{array}{c}-.02 * * * \\
(.00)\end{array}$ & - & - & $\begin{array}{c}-.02 * * * \\
(.00)\end{array}$ & - & - \\
\hline Self-transcendence values (ST) & - & $.00(.00)$ & - & - & $\begin{array}{l}.003 \\
(.002)\end{array}$ & - \\
\hline Self-enhancement values (SE) & - & - & $\begin{array}{r}.03 * * * \\
(.00)\end{array}$ & - & - & $\begin{array}{r}.03 * * * \\
(.00)\end{array}$ \\
\hline ST/SE values $\times$ finance industry $(0 / 1)$ & - & - & - & $.06 *(.04)$ & - & - \\
\hline ST values $\times$ finance industry $(0 / 1)$ & - & - & - & - & $.07 *(.04)$ & - \\
\hline SE values $\times$ finance industry $(0 / 1)$ & - & - & - & - & - & $-.05(.04)$ \\
\hline Finance industry $(0 / 1)$ & $.07 *(.04)$ & $\begin{array}{r}.07 * * \\
(.04)\end{array}$ & $.07 *(.04)$ & $.08 * *(.04)$ & $\begin{array}{r}.08 * * \\
(.04)\end{array}$ & $.08 * *(.04)$ \\
\hline No. of finance industry professionals in sample & 797 & 797 & 797 & 797 & 797 & 797 \\
\hline Total sample size & 211,531 & 211,531 & 211,531 & 211,531 & 211,531 & 211,531 \\
\hline$R^{2}$ & .00 & .00 & .00 & .00 & .00 & .00 \\
\hline
\end{tabular}

As described in the main text, the dependent variable is log-transformed by adding 1 to the number of subordinates and taking the natural logarithm of the resulting sum. A minus sign for the coefficient implies that the respondent has fewer subordinates. Continuous (non-dummy) variables (both dependent and independent) are standardized to have a mean of 0 and a standard deviation of 1 . Standard errors in parentheses $*, * *$ and $* * *$ denotes statistical significance at the 10,5 and $1 \%$ level 
SE values have a negative effect on career success relative to one's industry peers, the net effect in the finance industry is positive $(-0.02+0.06 \approx 0.04)$ (Model 4 ). More generally, effect sizes tend to be small, as expressed in small standardized coefficients and low variance explained.

\section{Robustness Checks}

As indicated in the previous section, we apply different tests to assess the robust of our baseline findings (Tables 3, $4,5)$.

\section{Controlling for Possible Confounders}

A most prominent challenge to the analyses presented in Table 2 is the possibility of an omitted variable bias. Specifically, a third variable may be associated both with individuals' values and with the likelihood that an individual works in the finance industry, for instance his/her level of education. If this is the case, there will be a bias in the coefficient for the interaction term that allows us to assess the culture in the finance industry vis-à-vis the culture in other industries. To deal with this issue, we estimate our main empirical models (Models 4-6), adding a variety of control variables, including, not least, years of education and total hours worked. Table 3 presents the results, where we again estimate separate models for ST/ SE, ST and SE values (Models 7-9).

Most relevant finding is that results again do not support H1. In fact, in all three cases, the sign of the coefficient for the interaction term is counter to H1. Moreover, in two out of three cases (Models 7 and 9) this coefficient not only has the wrong sign but is statistically significant at usual levels as well $(p<0.1)$. Meanwhile, we prefer the empirical model specification that includes control variables (Models 7-9) over the model specification that does not include control variables (Models 4-6), as the former specification allows for an analysis of the relationship between people's personal values and their career success that is unbiased by confounders. For the remainder of our analyses, we therefore always include control variables.

\section{Behavioral Measures Instead of Values}

A second challenge to our baseline analysis is that the SE and ST values that we consider really do not match the kind of malfeasances associated with the finance industry in

Table 3 Robustness check: control variables added and replacing dispositional measures of employee traits with behavioral measures

\begin{tabular}{|c|c|c|c|c|c|}
\hline \multirow[t]{2}{*}{ Dependent variable $=$ number of subordinates that respondent has } & \multirow[t]{2}{*}{ Model 7} & \multirow[t]{2}{*}{ Model 8} & \multirow[t]{2}{*}{ Model 9} & \multicolumn{2}{|c|}{ Behavioral measures } \\
\hline & & & & Model 10 & Model 11 \\
\hline Self-transcendence versus self-enhancement values (ST/SE) & $-.04 * * *(.00)$ & - & - & - & - \\
\hline Self-transcendence values (ST) & - & $-.02 * * *(.00)$ & - & - & - \\
\hline Self-enhancement values (SE) & - & - & $.04 * * *(.00)$ & - & - \\
\hline ST/SE values $\times$ finance industry $(0 / 1)$ & $.06^{*}(.03)$ & - & - & - & - \\
\hline ST values $\times$ finance industry $(0 / 1)$ & - & $.05(.03)$ & - & - & - \\
\hline SE values $\times$ finance industry $(0 / 1)$ & - & - & $-.05 *(.03)$ & - & - \\
\hline Insurance fraud & - & - & - & $.01 *(.01)$ & - \\
\hline Insurance fraud $\times$ finance industry $(0 / 1)$ & - & - & - & $-.01(.06)$ & - \\
\hline Tax fraud & - & - & - & - & $.03 * * *(.01)$ \\
\hline Tax fraud $\times$ finance industry $(0 / 1)$ & - & - & - & - & $-.07(.08)$ \\
\hline Finance industry $(0 / 1)$ & $-.05(.03)$ & $-.05(.03)$ & $-.05(.03)$ & $.15^{*}(.08)$ & $.14 *(.08)$ \\
\hline Years of education & $.15 * * *(.00)$ & $.15^{* * *}(.00)$ & $.15 * * *(.00)$ & $.19 * * *(.01)$ & $.19 * * *(.01)$ \\
\hline Total hours worked per week & $.17 * * *(.00)$ & $.17 * * *(.00)$ & $.17 * * *(.00)$ & $.16^{* * *}(.01)$ & $.16^{* * * *}(.01)$ \\
\hline Other control variables & Yes & Yes & Yes & Yes & Yes \\
\hline No. of finance industry professionals in sample & 797 & 797 & 797 & 137 & 140 \\
\hline Total sample size & 211,531 & 211,531 & 211,531 & 31,427 & 30,994 \\
\hline $\mathrm{R}^{2}$ & .14 & .14 & .14 & .14 & .14 \\
\hline
\end{tabular}

As described in the main text, the dependent variable is log-transformed by adding 1 to the number of subordinates and taking the natural logarithm of the resulting sum. A minus sign for the coefficient implies that the respondent has fewer subordinates. Continuous (non-dummy) variables (both dependent and independent) are standardized to have a mean of 0 and a standard deviation of 1 . The complete set of control variables is age, age squared, sex (dummy variable), educational degree (dummy variables), years of education (see table), total hours worked per week (see table), type of employment relation (dummy variables), and a complete set of country dummies. Standard errors in parentheses

$*$, ** and $* * *$ denotes statistical significance at the 10,5 and $1 \%$ level 
Table 4 Results for two alternative measures of individuals' career success

\begin{tabular}{|c|c|c|c|c|c|c|}
\hline & \multicolumn{3}{|c|}{$\begin{array}{l}\text { Dependent variable }=\text { level of authority } \\
\text { that respondent has }\end{array}$} & \multicolumn{3}{|c|}{$\begin{array}{l}\text { Dependent variable }=\text { position in the } \\
\text { corporate hierarchy }\end{array}$} \\
\hline & Model 12 & Model 13 & Model 14 & Model 15 & Model 16 & Model 17 \\
\hline $\begin{array}{l}\text { Self-transcendence versus self-enhancement values } \\
\text { (ST/SE) }\end{array}$ & $\begin{array}{l}-.02 * * * \\
(.00)\end{array}$ & - & - & $\begin{array}{l}-.02 * * * \\
(.00)\end{array}$ & - & - \\
\hline Self-transcendence values (ST) & - & $\begin{array}{l}-.02 * * * \\
(.00)\end{array}$ & - & - & $\begin{array}{l}-.02 * * * \\
(.00)\end{array}$ & - \\
\hline Self-enhancement values (SE) & - & - & $\begin{array}{r}.02 * * * \\
(.00)\end{array}$ & - & - & $\begin{array}{r}.01 * * * \\
(.00)\end{array}$ \\
\hline $\mathrm{ST} / \mathrm{SE}$ values $\times$ finance industry $(0 / 1)$ & $.00(.03)$ & - & - & $.071 * *(.03)$ & - & - \\
\hline ST values $\times$ finance industry $(0 / 1)$ & - & $-.01(.03)$ & - & - & $.05(.03)$ & - \\
\hline SE values $\times$ finance industry $(0 / 1)$ & - & - & $-.01(.03)$ & - & - & $\begin{array}{r}-.07 * * \\
(.03)\end{array}$ \\
\hline Finance industry $(0 / 1)$ & $.15 * * *(.03)$ & $.15^{* * *}(.03)$ & $\begin{array}{r}.15^{* * * *} \\
(.03)\end{array}$ & $.01(.03)$ & $.00(.03)$ & $.01(.03)$ \\
\hline Standard control variables & Yes & Yes & Yes & Yes & Yes & Yes \\
\hline No. of finance industry professionals in sample & 674 & 674 & 674 & 783 & 783 & 783 \\
\hline Total sample size & 182,553 & 182,553 & 182,553 & 206,174 & 206,174 & 206,174 \\
\hline$R^{2}$ & .34 & .34 & .34 & .17 & .17 & .17 \\
\hline
\end{tabular}

Continuous (non-dummy) variables (both dependent and independent) are standardized to have a mean of 0 and a standard deviation of 1 . The complete set of control variables is age, age squared, sex (dummy variable), educational degree (dummy variables), years of education (see table), total hours worked per week (see table), type of employment relation (dummy variables), and a complete set of country dummies. Standard errors in parentheses

$*$, ** and $* * *$ denotes statistical significance at the 10,5 and $1 \%$ level

general and the GFC in particular. However, replacing our values measures with behavioral measures concerning dishonest behavior, specifically insurance fraud or tax fraud, does not change the results (Models 10-11 in Table 3). Individuals that have committed insurance or tax fraud more often during the past 5 years enjoy less rather than more relative career success in the finance industry compared to other industries, although the difference is not statistically significant at usual levels.

\section{Alternative Measures of Individuals' Career Success}

While the number of subordinates that a person has is the main dependent variable in our analysis, we also want to make sure that this specific operationalization of individuals' career success is not somehow affecting our results. To assess the robustness of our baseline results for the specific operationalization chosen, we repeat our estimation of our preferred empirical models, meaning the empirical models that include control variables (Models 7-9 in Table 3).

Results are again robust (Table 4). Specifically, coefficients for the interaction terms are never both statistically significant and of the sign predicted by H1. In fact, there are only two cases out of six (Models 15 and 16) in which there is a statistically significant difference between the finance industry and other industries in the relationship between personal values and career success $(p<0.1)$. However, in both these cases, the sign is in the direction opposite to the direction predicted by $\mathrm{H} 1$, thus providing statistically significant evidence counter to this hypothesis.

\section{Potential Biases Resulting from Including Post-Crisis Data}

Since some of the data that we use have been collected after the start of the GFC in 2007, there is the potential that responses are biased by the intense, post-crisis debate on the finance industry's culture. We do not immediately see how this would cause a problem for the present analysis, given the indirect approach to assessing organizational culture that we employ. However, as indicated, we also check the robustness of our findings using a sample comprising only data collected before the start of the crisis.

As expected, results are largely the same as before (Models 18-20 in Table 5). The main difference is that we do not find statistically significant evidence counter to $\mathrm{H} 1$ as we did before, which is likely the result of having fewer FIs in the sample than before (380 vs. 797 for Models 7-9). Still, though, we do not find any evidence whatsoever supporting $\mathrm{H} 1$ either. 
Table 5 Robustness checks using pre-crisis data and a more narrow classification of finance professionals

\begin{tabular}{|c|c|c|c|c|c|c|}
\hline \multirow[t]{2}{*}{$\begin{array}{l}\text { Dependent variable }=\text { number of subordinates that } \\
\text { respondent has }\end{array}$} & \multicolumn{3}{|c|}{ Pre-crisis data } & \multicolumn{3}{|c|}{$\begin{array}{l}\text { More narrow classification of finance } \\
\text { industry professionals }\end{array}$} \\
\hline & Model 18 & Model 19 & Model 20 & Model 21 & Model 22 & Model 23 \\
\hline $\begin{array}{l}\text { Self-transcendence versus self-enhancement values (ST/ } \\
\text { SE) }\end{array}$ & $\begin{array}{c}-.05 * * * \\
(.003)\end{array}$ & - & - & $\begin{array}{l}-.04 * * * \\
(.00)\end{array}$ & - & - \\
\hline Self-transcendence values (ST) & - & $\begin{array}{l}-.03 * * * \\
(.00)\end{array}$ & - & - & $\begin{array}{l}-.02 * * * \\
(.00)\end{array}$ & - \\
\hline Self-enhancement values (SE) & - & - & $\begin{array}{r}.05^{* * * *} \\
(.00)\end{array}$ & - & - & $\begin{array}{r}.04 * * * \\
(.00)\end{array}$ \\
\hline ST/SE values $\times$ finance industry $(0 / 1)$ & $.02(.050)$ & - & - & $.05(.04)$ & - & - \\
\hline ST values $\times$ finance industry $(0 / 1)$ & - & $.06(.05)$ & - & - & $.03(.05)$ & - \\
\hline SE values $\times$ finance industry $(0 / 1)$ & - & - & $.01(.05)$ & - & - & $-.05(.04)$ \\
\hline Finance industry $(0 / 1)$ & $.02(.05)$ & $.02(.05)$ & $.01(.05)$ & $\begin{array}{l}-.13^{* * * *} \\
(.05)\end{array}$ & $\begin{array}{l}-.13 * * * \\
(.04)\end{array}$ & $\begin{array}{l}-.13 * * * \\
(.04)\end{array}$ \\
\hline Standard control variables & Yes & Yes & Yes & Yes & Yes & Yes \\
\hline No. of finance industry professionals in sample & 380 & 380 & 380 & 446 & 446 & 446 \\
\hline Total sample size & 92,249 & 92,249 & 92,249 & 211,531 & 211,531 & 211,531 \\
\hline$R^{2}$ & .15 & .15 & .15 & .14 & .14 & .14 \\
\hline
\end{tabular}

As described in the main text, the dependent variable is log-transformed by adding 1 to the number of subordinates and taking the natural logarithm of the resulting sum. A minus sign for the coefficient implies that the respondent has fewer subordinates. Continuous (non-dummy) variables (both dependent and independent) are standardized to have a mean of 0 and a standard deviation of 1 . The complete set of control variables is age, age squared, sex (dummy variable), educational degree (dummy variables), years of education (see table), total hours worked per week (see table), type of employment relation (dummy variables), and a complete set of country dummies. Standard errors in parentheses

$*, * *$ and $* * *$ denotes statistical significance at the 10,5 and $1 \%$ level

\section{A Different Classification of Professionals in the Finance Industry}

As a last robustness check, we apply a stricter criterion for classifying individuals as professionals working in the finance industry. Applying this stricter criterion reduces the total number of FIs in our sample from 797 (Tables 2, 3) to 446. Also in this case, however, results are largely unaffected (Models 21-23 in Table 5). Notably, the estimated coefficients for the interaction terms still go against $\mathrm{H} 1$, though they lack statistical significance at usual levels.

\section{Extension: Comparative Results for Selected Other Industries}

So far, our analysis has considered the finance industry visà-vis all other industries. However, to get a better sense of how exactly industries may differ in terms of the observed relationship between people's personal values and their career success, it is helpful to consider some other industries in detail as well. We have selected two such industries that fit with prior stereotypes as to the kind of organizational culture that they might have, highly appreciative of ST values and highly dismissive of SE values, and the other way around. The first industry concerns nursing and midwifery, which we expect to have an organizational culture that resonates better with individuals with strong ST values and weak SE values. Similarly, the second industry involves professionals working as retail or wholesale trade managers, which we expect to have an organizational culture that resonates better with individuals with strong SE values and weak ST values. ${ }^{5}$

Consistent with our stereotypical characterization of the two industries, results (Table 6) indicate that individuals with strong ST values/weak SE values enjoy statistically significant more career success relative to their peers in the nursing/midwifery industry vis-à-vis other industries, while individuals with strong SE values/weak ST values enjoy more career success relative to their peers working in retail or wholesale trade than when working in other industries. A most interesting finding is that, overall, inter-industry differences found are much more pronounced than the inter-industry differences found when comparing the finance industry with other industries. For nursing and

\footnotetext{
5 The group of Nursing or midwifery professionals comprises four ISCO categories: Nursing and midwifery professionals (ISCO88 2230); Nursing and midwifery professionals (ISCO08 2220); Nursing professionals (ISCO08 2221); and Midwifery professionals (ISCO08 2222). The group of Retail or wholesale trade managers comprises two ISCO categories: Managers in wholesale and retail trade (ISCO88 1224); and Retail and wholesale trade managers (ISCO08 1420).
} 
Table 6 A comparative perspective: results for two other industries

\begin{tabular}{|c|c|c|c|c|c|c|}
\hline \multirow{2}{*}{$\begin{array}{l}\text { Dependent variable }=\text { number of subordinates that } \\
\text { respondent has }\end{array}$} & \multicolumn{3}{|c|}{ Nursing or midwifery professionals } & \multicolumn{3}{|c|}{ Retail or wholesale trade managers } \\
\hline & Model 24 & Model 25 & Model 26 & Model 27 & Model 28 & Model 29 \\
\hline $\begin{array}{l}\text { Self-transcendence versus self-enhancement values (ST/ } \\
\text { SE) }\end{array}$ & $\begin{array}{c}-.04 * * * \\
(.00)\end{array}$ & - & - & $\begin{array}{c}-.04 * * * \\
(.00)\end{array}$ & - & - \\
\hline Self-transcendence values (ST) & - & $\begin{array}{c}-.02 * * * \\
(.00)\end{array}$ & - & - & $\begin{array}{l}-.02 * * * \\
(.00)\end{array}$ & - \\
\hline Self-enhancement values (SE) & - & - & $\begin{array}{r}.04 * * * \\
(.00)\end{array}$ & - & - & $\begin{array}{r}.04 * * * \\
(.00)\end{array}$ \\
\hline ST/SE values $\times$ nursing or midwifery professional $(0 / 1)$ & $.08 * * *(.02)$ & - & - & - & - & - \\
\hline ST values $\times$ nursing or midwifery professional $(0 / 1)$ & - & $.08 * * *(.02)$ & - & - & - & - \\
\hline SE values $\times$ nursing or midwifery professional $(0 / 1)$ & - & - & $\begin{array}{c}-.06 * * \\
(.02)\end{array}$ & - & - & - \\
\hline ST/SE values $\times$ retail or wholesale trade $(0 / 1)$ & - & - & - & $-.06(.04)$ & - & - \\
\hline ST values $\times$ retail or wholesale trade $(0 / 1)$ & - & - & - & - & $-.04(.04)$ & - \\
\hline SE values $\times$ retail or wholesale trade $(0 / 1)$ & - & - & - & - & - & $.06(.04)$ \\
\hline Nursing or midwifery professional $(0 / 1)$ & $.30 * * *(.02)$ & $.29 * * *(.02)$ & $.31(.02)$ & - & - & - \\
\hline Retail or wholesale trade $(0 / 1)$ & - & - & - & $\begin{array}{l}1.18 * * * \\
(.04)\end{array}$ & $\begin{array}{l}1.19 * * * \\
(.04)\end{array}$ & $\begin{array}{l}1.19 * * * \\
(.04)\end{array}$ \\
\hline Standard control variables & Yes & Yes & Yes & Yes & Yes & Yes \\
\hline Number of professionals in sample & 1523 & 1523 & 1523 & 636 & 636 & 636 \\
\hline Total sample size & 211,531 & 211,531 & 211,531 & 211,531 & 211,531 & 211,531 \\
\hline$R^{2}$ & .14 & .14 & .14 & .15 & .15 & .15 \\
\hline
\end{tabular}

As described in the main text, the dependent variable is log-transformed by adding 1 to the number of subordinates and taking the natural logarithm of the resulting sum. A minus sign for the coefficient implies that the respondent has fewer subordinates. Continuous (non-dummy) variables (both dependent and independent) are standardized to have a mean of 0 and a standard deviation of 1 . The complete set of control variables is age, age squared, sex (dummy variable), educational degree (dummy variables), years of education (see table), total hours worked per week (see table), type of employment relation (dummy variables), and a complete set of country dummies. Standard errors in parentheses

$*$, ** and *** denotes statistical significance at the 10,5 and $1 \%$ level

midwifery professionals, for instance, we find a coefficient for the interaction term involving ST values of 0.08 (Model 25 in Table 6), which is more than $50 \%$ larger than the coefficient of 0.05 that we found for professionals in the finance industry (Model 8 in Table 3). Moreover, whereas SE values had a more negative effect on career success in the finance industry than in other industries (Model 9 in Table 3), SE values have a more positive effect on career success in retail or wholesale trade than in other industries (Model 29 in Table 6). ${ }^{6}$ Most important finding of the above exercise, however, is that our indirect method for assessing organizational culture appears quite capable of picking up important differences in the organizational culture in different industries.

\footnotetext{
${ }^{6}$ To be complete, the coefficient for this last effect lacks statistical significance at usual levels $(p=0.11)$, even though the absolute size of the coefficient in Model 29 (0.06) is larger than the absolute size of the coefficient in Model 9 (0.05). Explanation for the lower statistical significance despite a larger effect size is that the number of retail or wholesale trade managers is lower than the number of professionals working in the finance industry, 636 versus 797.
}

\section{Discussion}

Overall, our results do not reveal any evidence that supports the proposition that the culture in the finance industry is unique in a way that implicates this culture in the GFC. While the idea that the culture in the finance industry is partly to blame for the GFC has been hugely popular and larded with anecdotes (e.g., Fox 2010; Friedman 2011), our results present no indication whatsoever that the finance industry's culture indeed stands out from the culture in other industries in terms of fostering malfeasance. We have empirically assessed whether the culture in the finance industry deviates significantly from other industries in the sense that employees need to have strong self-enhancement values and weak self-transcendence values in order to be successful in this industry. Results, however, unambiguously indicate that this is not the case. Instead, the opposite appears to hold, which is that strong self-enhancement (Power and Achievement) values and weak self-transcendence (Benevolence and Universalism) values go together with less relative career success in the finance industry compared to other industries. 
Clearly, the indirect method for assessing organizational culture that we have used, comparing the values-success relationship found for the finance industry with the valuessuccess relationship found for other industries, can be a limiting factor. Notably, results might depend on the particular relationships and measures that we have considered in the empirical analysis. However, extensive checks indicate that our results are robust to using a range of alternative operationalizations and measures of our key dependent and independent variables, not least various alternatives by which to measure individuals' career success. Hence, the conclusion following our empirical analysis is simply that, since the culture in the finance industry does not resonate well with professionals that seek to pursue their own personal gain at the expense of others, the finance industry's culture cannot be blamed for the GFC.

\section{Conclusion}

Given that finance plays a central role in the daily lives of individuals and organizations alike, a fundamental question following the global financial crisis (GFC) is how the financial system can be improved to decrease the likelihood of future crises and optimize the intermediation between suppliers of credit and credit seekers. A factor often highlighted as one of the chief culprits in the GFC is the culture in the finance industry, which is said to have fostered the widespread malfeasances that brought down the financial system. This paper has provided a systematic assessment of the finance industry's culture in relation to the GFC.

In the wake of the GFC, the culture in the finance industry has been fiercely debated. A main challenge for our study has therefore been that quasi-experiments or survey measures cannot be readily used, as being subject of intense criticism is likely to bias people's behavior in such experiments or their answers to culture-related survey questions. We have sought to overcome this challenge by developing a novel method for assessing the culture of an organization (or in an industry) that does not consider culture directly but focuses on the relationship between employees' personal traits and their career success in the organization (or industry) under study. With strong theoretical roots in the large literature on the effects of $\mathrm{P}-\mathrm{O}$ fit on employee outcomes, the idea behind this ex-post method is that we can infer a great deal about the culture of an organization by simply observing which personal traits help or hamper individual employees to be successful in this organization. The actual assessment of organizational culture subsequently does not revolve around measures or scores collected directly from the people concerned, as is typical in the literature (e.g., through employee surveys), but around inter-organizational (or cross-industry) variation in the relationship between personal traits and employee outcomes.

We have applied this method to assess the proposition that the culture in the finance industry is partly to blame for the GFC because it has been uniquely conducive to organizational members behaving unethically. Empirical results subsequently indicated systematic differences between the finance industry and other industries in terms of the extent to which employees' so-called self-enhancement values (i.e., values emphasizing the pursuit of private gain) and so-called self-transcendence values (i.e., values emphasizing caring for others) are associated with career success relative to one's industry peers. However, in all cases, the finance industry appeared less appreciative of self-enhancement and more appreciative of self-transcendence than other industries are. Hence, we did not find any sort of cross-industry differences that would implicate the finance industry's culture in the GFC.

Based on these findings, we conclude that the organizational culture in the finance industry has not been a significant factor in the GFC. This conclusion, in turn, has important implications for reforms meant to improve the current financial system. The GFC has helped uncover important weaknesses of the financial system that make the system vulnerable to crises and undermine its ability to provide efficient intermediation between suppliers of credit and organizations and individuals seeking credit. Accordingly, and given the sector's real-life importance, improving the financial system is high on political agenda's worldwide. Following the debate highlighting the finance industry's culture as one of the chief culprits in the GFC, many pundits have thereby proposed cultural change as key to improving the financial system. Our results, in contrast, indicate that cultural change has only limited potential to improve the financial system. Because the culture in the finance industry does not stand out from the culture in other industries, it is not realistic to expect that changing the industry's culture would somehow lead to a drastic reduction in malfeasance by employees working in the sector. Instead, it makes more sense for financial reforms to target formal governance structures and regulations in the industry, as these apparently leave a lot of room for dishonesty and unethical behavior more broadly. Our analysis thus contributes an important practical insight, which is that attention should shift away from cultural change toward other types of financial sector reforms that promise to be much more potent in improving the financial system.

A second contribution of this paper comes in the form of the novel method for assessing organizational culture that we have developed. Focusing on relationships between employees' personal traits and their career success in the industry or organization under study, this method differs 
substantially from traditional approaches to measuring organizational culture. This difference, in turn, has both advantages and disadvantages. The method's most notable advantages are its wide applicability-all that is required are data on personal traits and work outcomesand the fact that it is indirect, which provides shielding from different types of (response) biases. A first, practical disadvantage is that the method is data intensive, requiring detailed information on both personal traits and work outcomes for a large group of employees. A second, conceptual disadvantage is that our ex-post method does not clearly delineate what exactly it is about industries or organizations, which is driving the observed differences in the relationship between employees' personal traits and their career success. We have taken these differences as reflecting differences in organizational culture. However, strictly speaking, these differences could also be reflecting differences in, for instance, organizational climate. For the purpose of this paper, nothing is lost by not explicitly distinguishing between culture and climate as both are concerned with describing organizational environments and, at any rate, are strongly related (Denison, 1996). Nevertheless, future research may work on thinking about how conceptually distinct elements of organizational environments may get expressed in relationships between different sets of personal traits and employee outcomes. More generally, we think that our indirect approach to assessing organizational culture needs further development before it can realize its full potential as a valuable addition to the existing toolkit for studying organizational cultures, especially when other methods are likely to elicit biased information from the employees concerned. A particularly interesting and important topic for future research is to theorize on the set of interrelationships between employee traits and outcomes that can be combined as a way of providing a comprehensive characterization of organizations' culture (or climate for that matter). Extant frameworks of organizational culture have identified a variety of different dimensions of organizational culture, and it would be interesting to relate features of organizations' culture expressed in trait-outcome relationships to the cultural dimensions identified in such earlier work.

Acknowledgments The author is grateful to Vincent Kunst and Kees van Veen for helpful comments and suggestions.

Open Access This article is distributed under the terms of the Creative Commons Attribution 4.0 International License (http://crea tivecommons.org/licenses/by/4.0/), which permits unrestricted use, distribution, and reproduction in any medium, provided you give appropriate credit to the original author(s) and the source, provide a link to the Creative Commons license, and indicate if changes were made.

\section{References}

Anderson, C., Spataro, S. E., \& Flynn, F. J. (2008). Personality and organizational culture as determinants of influence. Journal of Applied Psychology, 93, 702-710.

Ashkanasy, N., Broadfoot, L. E., \& Falkus, S. (2000). Questionnaire measures of organizational culture. In N. M. Ashkanasy, C. P. M. Wilderom, \& M. F. Peterson (Eds.), Handbook of organizational culture and climate. Thousand Oaks: Sage Publications.

Boddy, C. R. (2011). The corporate psychopaths theory of the global financial crisis. Journal of Business Ethics, 102, 255-259.

Bower, M. (1966). The will to manage. New York: McGraw Hill.

Central Bank of Ireland. 2012. Central Bank of Ireland, Strategic Plan 2013-2015. https://www.centralbank.ie/publications/Docu ments/Central\%20Bank\%20of\%20Ireland\%20Strategic\%20Plan \%202013\%20-\%202015.pdf.

Chapman, D. S., Uggerslev, K. L., Carroll, S. A., Piasentin, K. A., \& Jones, D. A. (2005). Applicant attraction to organizations and job choice: A meta-analytic review of the correlates of recruiting outcomes. Journal of Applied Psychology, 90, 928-944.

Cohn, A., Fehr, E., \& Maréchal, M. A. (2014). Business culture and dishonesty in the banking industry. Nature, 516, 86-89.

Cohn, A., Maréchal, M. A., \& Noll, T. (2015). Bad boys: How criminal identity salience affects rule violation. Review of Economic Studies, In press.

Crane, A. (1999). Are you ethical? Please tick yes $\square$ or no $\square$ on researching ethics in business organizations. Journal of Business Ethics, 20, 237-248.

Davis, G. F., \& Kim, S. (2015). Financialization of the economy. Annual Review of Sociology, 41, 203-221.

Deal, T. E., \& Kennedy, A. A. (1982). Corporate cultures: The rites and rituals of corporate life. Reading: Addison-Wesley.

Denison, D. R. (1996). What is the difference between organizational culture and organizational climate? A native's point of view on a decade of paradigm wars. Academy of Management Review, 21, $619-654$.

England, G. W., \& Lee, R. (1974). The relationship between managerial values and managerial success in the United States, Japan, India, and Australia. Journal of Applied Psychology, 59, 411-419.

Esser, I., \& Olsen, K. M. (2012). Perceived job quality: Autonomy and job security within a multi-level framework. European Sociological Review, 28, 443-454.

Financial Conduct Authority. (2014). Financial conduct authority, business plan 2014/15. https://www.fca.org.uk/static/documents/ corporate/business-plan-2014-2015.pdf.

Financial Crisis Inquiry Commission. (2011). Financial crisis inquiry report. http://fcic-static.law.stanford.edu/cdn_media/fcic-reports/ fcic_final_report_full.pdf.

Fox, J. (2010). Cultural change is key to bank reform. Financial Times, March 25, http://www.ft.com/cms/s/0/6966893c-384711df-8420-00144feabdc0.html\#axzz3fqlsP1Q5.

Friedman, T. L. (2011). Did You Hear the One About the Bankers? New York Times, October 29, http://www.nytimes.com/2011/ 10/30/opinion/sunday/friedman-did-you-hear-the-one-about-thebankers.html.

George, D., \& Mallery, P. (2003). SPSS for Windows step by step: A simple guide and reference, 11.0 update (4th ed.). Boston: Allyn \& Bacon.

Hackman, R. J., \& Oldham, G. R. (1975). Development of the Job diagnostic survey. Journal of Applied Psychology, 60, 159-170.

Heckman, J. (1979). Sample selection bias as a specification error. Econometrica, 47, 153-161. 
Jowell, R., \& Central Co-ordinating Team. (2007). European social survey 2006/2007: Technical report. London: Centre for Comparative Social Surveys.

Krippner, G. R. (2005). The financialization of the American economy. Socioeconomic Review, 3, 173-208.

Kristof, A. L. (1996). Person-organization fit: An integrative review of its conceptualization, measurement, and implications. Personnel Psychology, 49, 1-49.

Kristof-Brown, A. L., Zimmerman, R. D., \& Johnson, E. C. (2005). Consequences of individuals' fit at work: A meta-analysis of person-job, person-organization, person-group, and personsupervisor fit. Personnel Psychology, 58, 281-342.

Lewis, M. (2010). The big short: Inside the doomsday machine. New York: W.W. Norton \& Company.

Matsumoto, D., \& Van de Vijver, F. J. R. (Eds.). (2011). Crosscultural research methods in psychology. New York: Cambridge University Press.

O'Reilly, C. A., Chatman, J., \& Caldwell, D. (1991). People and organizational culture: A profile comparison approach to assessing person-organization fit. Academy of Management Journal, 34, 487-516.

Pettigrew, A. M. (1979). On studying organizational cultures. Administrative Science Quarterly, 24, 570-581.

Randall, D. M., \& Fernandes, M. F. (1991). The social desirability response bias in ethics research. Journal of Business Ethics, 10, 805-817.

Roulet, T. (2015). "What Good is Wall Street?" Institutional contradiction and the diffusion of the stigma over the finance industry. Journal of Business Ethics, 130, 389-402.

Santoro, M. A., \& Strauss, R. J. (2012). Wall street values: business ethics and the global financial crisis. Cambridge: Cambridge University Press.

Schein, E. H. (1992). Organizational culture and leadership (2nd ed.). San Francisco: Jossey Bass.

Schneider, B. (1987). The people make the place. Personnel Psychology, 40, 437-453.

Schwartz, S. H. (1992). Universals in the content and structure of values: Theory and empirical tests in 20 countries. In M. Zanna (Ed.), Advances in experimental social psychology (Vol. 25). New York: Academic Press.
Schwartz, S. H. (2009). Basic human values. Paper for the crossnational comparison seminar on the quality and comparability of measures for constructs in comparative research: Methods and Applications. Bolzano, Italy, June 10-13.

Schwartz, S. H., \& Bilsky, W. (1987). Toward a universal psychological structure of human values. Journal of Personality and Social Psychology, 53, 550-562.

Schwartz, S. H., Melech, G., Lehmann, A., Burgess, S., \& Harris, M. (2001). Extending the cross-cultural validity of the theory of basic human values with a different method of measurement. Journal Cross-Cultural Psychology, 32, 519-542.

Shadish, W. R., Cook, T. D., \& Campbell, D. T. (2002). Experimental and quasi-experimental designs for generalized causal inference. Boston: Houghton Mifflin Company.

Slater, S. (2011). Factbox-UBS trader joins rogues' gallery of financial crime. Reuters, September 15, http://uk.reuters.com/ article/2011/09/15/uk-ubs-factbox-idUKTRE78E1A920110915.

Stiglitz, J. E., \& Members of a UN Commission of Financial Experts. (2010). The stiglitz report: Reforming the international monetary and financial systems in the wake of the global crisis. New York: New Press.

Tirole, J. (1996). A theory of collective reputations (with applications to the persistence of corruption and to firm quality). Review of Economic Studies, 63, 1-22.

Van Hoorn, A. (2012). Cross-cultural experiments are more useful when explanans and explanandum are separated. Proceedings of the National Academy of Sciences, 109, e1329.

Van Hoorn, A. (2015). The global financial crisis and the values of professionals in finance: An empirical analysis. Journal of Business Ethics, 130, 253-269.

Watson, J., \& Williams, J. (1977). Relationship between managerial values and managerial success of Black and White managers. Journal of Applied Psychology, 62, 203-207.

Werner, A. (2014). 'Margin Call': Using film to explore behavioural aspects of the financial crisis. Journal of Business Ethics, 122, 643-654.

Zerbe, W. J., \& Paulhus, D. L. (1987). Socially desirable responding in organizational behavior: A reconception. Academy of Management Review, 12, 250-264. 